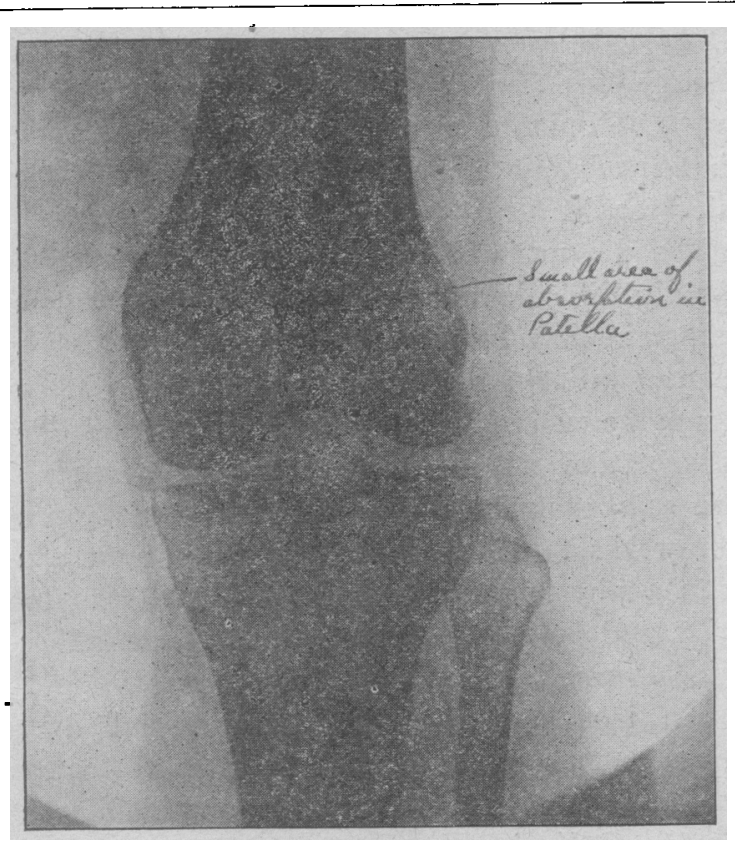

FIG. 5.-Radiograph of patella taken Anril 20, 1920. The arrow points to the area of absorption in the patella.

showed a definite cavity below the periosteum of the ulna containing a definite sequestrum, with the periosteum thickened above. In the left patella, there was a small area one-fourth of an inch in diameter, of lessened density near its distal margin. She was admitted to the Deaconness Hospital April 25th for operation.

Operation-April 26, 1920: A three-inch incision was made in the axis of the forearm immediately along the apex of the swelling, on the extensor surface of the ulna. A cavity was opened containing two teaspoonfuls of thin, light greenish pus. A culture was taken. The incision was carried down to the bone, and the periosteum stripped sideways, revealing a definite opening through the periosteal shell into a cavity beneath. The bony roof of this cavity was removed with a gouge and it was seen to be lined with grayish tissue and to contain a thin sliver-like sequestrum lying in a trough-like hollow in the ccrtex. This was removed and all projecting bits of bone chiselled away, the cavity being converted into a shallow depression. Two No. 4 Dakin tubes were placed in the bottom of the wound and several silk worm-gut sutures were placed, to be tied later.

With a completely new sterile outfit, an incision was made one and one-half inches long, over the mid line of the patella. There was definite edema of the soft parts and thickening of the periosteum at the lower border, where the patellar tendon attached. This was separated down to the bone, a small cavity found in the surface of the patella, about one-fourth inch in diameter, filled with grayish granulation tissue, but no pus. This was curetted out, down to healthy bone. Culture was taken. A small gauze drain was placed in the wound and the latter sutured about it.
The patient showed no reaction following the operation, the temperature not passing $99^{\circ}$. The forearm wound cleaned up rapidly with two hourly instillations of Dakin's solution, and four days after the operation, the tubes were removed and the sutures tied. The drain was removed from the knee wound at the end of twenty-four hours. Both wounds were completely healed by May 7 th, and the patient was walking about without pain, and the elbow motions normal. She was seen on May 14th, when she was completely well. All dressings were removed, and she was asked to report only in case of further trouble.

Dr. Francis L. Burnett reports that the specimen consisted of two swabs, and a bit of bone; one of the swabs was taken from the forearm, the other from a lesion on the knee; and the bit of bone was removed from the elbow. Culture tubes of bouillon were inoculated, but only in the tube containing the bone was there any growth apparent. This, on further examination, proved to be a pure culture of Bacillus Typhosus.

REFERENCES.

1 Osler: John Hopkins Hosp. Reports, Vol. iv, 1895, 73.

2 Rogers: Boston Medical and SuRgical Journal, March 6, 1913, p. 348.

Carnett: Annals of Surg., April, 1915.

- Fluss: Zentralbl. $f$. Grenzgebiete d. Med. u. Chir., 1905, 8, Bd. 5.645 .

- Riohardson: Jour, Baston Soc. Med. Sc., Vol, v 1900, 116

7 Jiohardson: Jour. Boston Soc. Med. Sc., Vol. v, 190

B Keen: Surg. Complications and Sequels of Typhoid Fever. W. B. Keen: Surg. Comp.

Dachtles: Am. Jour. Roent., April, 1914.

\section{LIPOMA OF THE MESENTERY.}

\section{By B. H. Alton, M.D., Wol.cester, Mass.}

Assistant Surgeon to the Memorial Hospital.

THE infrequent occurrence of solid tumors of the mesentery leads me to report this case of lipoma.

CASE 3061-1919. Mrs. M., aged 60, came to me because of constipation and an uncomforta. ble feeling in the abdomen. She had been married 39 years, and had four children living and well; three died in infancy. She had always been a rather delicate woman, having more or less stomach trouble. An appendectomy was done in 1909. Adhesions about the appendix region were dissected in 1915 . Hemorrhoidectomy 18 years ago. Since the last operation, her condition has been fairly good up to September, 1919. She then began to tire easily and have an "all gone" feeling in her abdomen, together with constipation. These symptoms have increased during the past four or five months. Menopause at the age of 45 . Slight vaginal discharge during the past year. 
A curettage of the cervix and uterus was done. The curettings showed no evidence of malignant disease.

Patient entered hospital in October, 1919. The physical examination revealed a fairly well developed and nourished woman lying comfortably in bed. There was a scar of an old rectus incision on the lower abdomen. A kidney-shaped tumor could be felt over the left kidney extending across the mid-line and downward about five inches. It was slightly movable and tender when a small amount of pressure was used. Vaginal examination was negative.

The urine was straw colored, acid, specific gravity 1014, slight trace of albumen,- - sediment showed an occasional leucocyte and many squamous cells. A mild cystitis that cleared up under treatment. Kidneys showed a function test of $45 \%$. The haemoglobin was $90 \%$ and the leucocytes 7800 . The blood Wassermann test was negative. A roentgenogram of the abdomen showed a mass about the size of the fist in the left kidney region, but it did not appear to be connected with the kidney. It was thought that the tumor was attached to the mesentery.

On October 11, 1919, the abdomen was opened by a mid-line incision over the mass. A firm, oblong, smooth tumor was found lying in the root of the mesentery. This tumor was pale yellow in color, showing small ramifications extending upward and downward. The mass was about five inches long, three inches wide, and about one and one-half inch thick. On closer examination, it was found that the larger vessels supplying the mesentery were enmeshed in the tumor. No attempt was made to remove the tumor, as the greater part of the blood supplv to the intestines passed through it. A specimen was removed for a pathological examination. The pelvic organs were normal and there were no other tumors in the abdomen. The abdomen was closed in layers with catgut. The patient had an uneventful recovery and was discharged from the hospital on the twelfth day.

Pathological report: Small piece of tissue, resembling fat tissue.

Microscopic: Specimen consists of fat tissue, in places showing the embryonic form of fat cellis.

Diagnosis: Lipoma.

In a communication received from the patient one year after operation, she states that she still has some abdominal pain and constipation, but that her general health was much improved.

Of the solid tumors of the mesentery, the lipomata are the most common. 'In 1905, Bowers described a mesenteric lipoma. Harris and Herzog, who reviewed 56 cases, collected from the literature up to 1897 , and added one of their own, state that 16 were diagnosed carci- noma; 15 lipoma; 7 sarcoma; and 6 fibroma; the diagnosis in the remainder was either mixed types or indefinite. Harris and Herzog believe that probably none of the diagnoses were microscopic.

The diagnosis of tumors of the mesentery is usually difficult and often impossible. Abdominal pain may be present and severe enough to suggest biliary, renal or appendicular colic, or it may be entirely absent. Greer cites pain and constipation as the most constant symptoms, and says that the tumor may be noted from a few weeks to 15 years before the patient consults a physician. The mass is usually to the right and below the umbilicus, and not adherent. Doran believes that diagnosis is impossible in most cases. In the differential diagnosis, confusion has existed with cysts of the ovary, pancreas, tumors of the liver, enlargements and displacements of the kidney, hydrops of the gall-bladder, and growths of the bowel itself. Because of their rarity, these growths are little considered in the diagnosis of abdominal tumors. From a practical viewpoint, the important thing is the recognition of the presence of a tumor and its prompt removal.

The surgical procedure, whether enucleation alone or combined with intestinal resection, cannot be determined until the tumor is exposed. Resection requires more time, adds to the surgical risk, and should be avoided whenever possible. Bigelow and Forman state that in those cases in which the tumor bulges the mesentery chiefly on one side and the overlying gut is consequently placed laterally, it may be possible to enucleate the. growth without dangerous interference with the blood supply. If the overlying gut is more centrally placed, the tumor bulging both leaves of the mesentery equally, or if the gut is adherent to the growth at its wall and involved in the process, resection should be proceeded with at once. Successful cases where enterectomy was combined with the removal of a mesenteric sarcoma, have been reported by Harris and Herzog, Sawyer, Mathews and others. The length of the intestine removed has varied from one half an inch to eight feet and two inches. That the question of resection is not necessarily determined by the size of the tumor is evidenced by the case cited by Bowers, where a fibroma weighing 30 pounds was successfully enucleated.

In a series of 27 cases, collected by Vance, there were 16 recoveries and 11 deaths, a mor- 
tality of $41 \%$. Seven of these tumors were sarcomata, and only one of the patients recovered. Unquestionably, the mortality is higher in these instances in which the tumor proves to be malignant than in the berign forms of fibroma and lipoma, which make up the greater number of the reported cases.

Greer eredits Horstuus (1578-1636) with reporting the first mesenteric tumor found at necropsy, and Bricheteau with reporting the first fibroma, in 1824. Bigelow and Forman, in a recent paper, state that about 100 cases of solid mesenteric tumors have been reported up to the present time.

\section{BIBLIOGRAPHY,}

Bowers, L. G.: Tumors of the Mesentery. Brit. Med. Jour., 1904, ii, 1075-1081.

Harris, M. L., and Herzog, M.: Solid Mesenteric Tumors. Ann. of Surg., 1897, xxvi, 66.82

Doran, A.: Fibroma of the Mesentery. Brit. Med. Jour., 1904, ii, 1075-1081.

Bigelow, L. L., and Forman, J.: Lymphosarcoma of the Mesentery. Ann. of Surg., 1920, lxxi, 11-15.

Judd, E. S., and McVay, J. R.: Fibromyoma of the Mesentery. Surg., Gyn., and Obstet., 1920, xxxi, 372-376.

Surg., Gyn., and Obstet., 1920, xxxi, 372-376. lxiii, 366-370.

Ixiii, 366-370. Fibromatous Tumors of the Mesentery. Brit reer, W. J.: Fibromatous

Jour., 1911, ii, 1085-1089. Shepherd, F. J.: Successiul Removal of an Enormous Mesenteric
Tumor and Nearly Eight Feet of Intestine. Brit. Med. Jour., 1897. ii, $966-968$

\section{PERFORATION OF MECKEL'S DIVERTI CULUM OF JEJUNUM.}

\section{By Thomas R. Donovan, M.D., Fitchburg, Mass.}

Perforation due to piece of metal. Report of case.

Boy, aged eleven. Family history negative. Past history negative. Present illness began at four A.M., July 8th, when child was awakened with acute abdominal pain and vomiting. Seen by his physician at this time and examination showed marked tenderness right side of abdomen, especially at a point about one inch above McBurney's. Temperature normal, pulse 90. Slight degree of rigidity right rectus muscle. Patient given an enema with considerable relief of symptoms. Child was seen by me at four P.M. of same day. Temperature $100 \%$ /1, pulse 120. Complaining of slight amount of abdominal pain but was apparently not suffering to any marked extent as he was up and about the house when I saw him. Examination showed a well developed and nourished boy about eleven years old. Tongue heavily coated and moist. Chest normal shape. Heart and lungs negative. Abdomen showed muscular spasm of slight degree of right rectus with a point of tenderness which was not marked, about one inch above McBurney's. No distention, no vomiting, no mass palpable. Diagnosis of probable acute appendicitis was made and operation advised.

Operation. Right rectus incision. Abdominal cavity entered behind muscle. Considerable cloudy fluid, slightly yellow, and somewhat resembling stomach contents found on opening peritoneum. Examination of intestines showed a condition of diffused peritonitis. Appendix was found to be normal. On exploring the abdominal cavity a hard mass about the size of a hazel nut was felt high up, in the region of the gall-bladder. This mass was freely moveable and when brought out of the abdominal cavity was found to be a Meckel's diverticulum attached to the base of a loop of small bowel, which from its blood supply and location, I judged to be jejunum. The tip of the diverticulum was buried in the distal end of the loop in a mass of adhesions and omentum and was covered with lymph. Upon freeing the end of the diverticulum the intestinal contents oozed out and the tip was seen to be perforated and gangrenous. Complete excision of the diverticulum with plastic repair of the opening into the intestine was done. Abdominal wound closed with drainage. Patient put up in Fowler's position and given Murphy drip. On the second day the boy developed a postoperative broncho-pneumonia, but in spite of this, he came along very nicely and was discharged well July 21 st.

The specimen was sent to Harvard University for pathological examination and the following report from Dr. J. H. Wright was given :

"A diverticulum of the small intestine about $1 \frac{1}{4} \times 3 / 4$ inches with a perforation at tip. Presenting in the perforation is a thin sheet of metal about $1 / 2 \times 1 / 2$ inch and a small fraction of an inch thick. The metal has a tin or silver sheen when scraped.

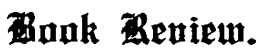

Physiological Chemistry. By Albert P. MathEws, Pн.D. Third Edition. Illustrated. New York: William Wood and Company. 1920.

Previous editions of this text-book and man ual for students have been favorably reviewed in the JourNaL. In this third edition, the practical part has been rearranged and largely rewritten; many new and important methods have been added, especially those of blood an. alysis; and many revisions have been made, particularly and most extensively in the chapter on vitamines. The book is stimulative and original in its treatment of what seems to many a highly, technical subject. 